\title{
Globalização e desigualdade: questões de conceituação e esclarecimento ${ }^{1}$
}

GÖRAN THERBORN

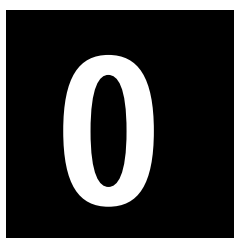

termo "Globalização" deveria ser utilizado como um conceito multidimensional e histórico que aponta para tendências, para dimensões mundiais, para o impacto, para conexões mundiais e fenômenos sociais, bem como para uma consciência global dos atores sociais. A desigualdade acontece de diversas formas e em diferentes grupos sociais, além disso, deve ser concebida como multidimensional. 0 conceito de "capacidade" (ou oportunidades vitais) de Amartya Sen constitui um importante ponto de partida. A desigualdade assume diferentes formas sociais, que derivam de modos distintos de produzir valores. As principais são a exploração, hierarquia, exclusão e segmentação.

Traçou-se um marco de referência geral com o objetivo de explicar os resultados distributivos globais e multidimensionais, distinguindo-se quatro tipos de processos: a história global, os fluxos globais- de comércio, de capital, de populações e de conhecimento -, uniões globais, articulando instituições e políticas nacionais com organizações e pressões transnacionais - e, finalmente, processos nacionais.

U ma avaliação do peso relativo desses processos mostra que a história global e os processos nacionais são os mais importantes, com uma diferenciação clara entre estados fortes e débeis. Enquanto a história, reproduzida pelosfluxos de comércio, de capital e de migração, acumulou

1 Esse paper é uma primeira versão, apresentada no Terceiro Encontro Internacional de Economistas sobre Problemas de Globalização e Desenvolvimento ocorrido em Havana, 29 de janeiro a 2 de fevereiro de 2001. 0 original em Inglês foi traduzido por Roberto Costa e revisado por Eurídice Baumgarten.

* Swedish Collegium for Advanced Study in the Social Sciences, U ppsala. 
a desigualdade econômica, o fluxo de conhecimento, sobretudo o médico, favoreceu uma maior igualdade, observando-se também novas transformações no sentido dos fluxos globais e seus efeitos distributivos.

A globalização, até este momento, não desfez o fortalecimento secular do estado-nação do Século XX, e a importância das relações inter-estatais significa que a cidadania é uma das mais importantes instituições mundiais de desigualdade. Por outro lado há estados que abrigam dentro de suas fronteiras quase tanta desigualdade econômica quanto a existente no mundo.

0 título do artigo refere-se a três conjuntos de questões fundamentais e controvertidas, não resolvidas entre os cientistas sociais, para não falar dos cidadãos sociais. Duas delas são basicamente conceituais e teóricas, a outra é, ao mesmo tempo, conceitual e empírica.

Em primeiro lugar, o que é globalização? De que forma devemos conceitualizá-la? Em segundo, que tipos de desigualdade podem ser identificados e quais são os mais pertinentes? $\mathrm{E}$, em terceiro lugar, que tipos de processos geram a desigualdade global que estamos observando e vivenciando?

$N$ ão podemos esperar encontrar uma resposta direta para qualquer dessas perguntas, já que nenhuma delas a tem. O s objetivos deste artigo são o de contribuir para o esclarecimento das alternativas, bem com de eventuais implicações para a sua adoção, propor uma determinada abordagem conceitualanalítica e apresentar argumentosempíricos para uma abordagem multifacetada sobre a geração de desigualdade no mundo. A globalização e a desigualdade são duas encruzilhadas das ciências so ciais e da filosofia social, abordadas aqui pelo autor a partir de sua formação como sociólogo e cientista político.

\section{0 que é globalização?}

Basicamente, há três respostas para esta pergunta. A mais evidente e mais simples delas é: a globalização é qualquer coisa que queiramos que ela seja, o que é uma resposta coerentemente 
nominalista. U m conceito é uma ferramenta e não uma essência, contudo, a resposta está sujeita a duas restrições imediatas, uma delas relacionada à comunicação, e a outra, à cognição. No caso de você querer comunicar-se com outras pessoas, uma definição idiossincraticamente original tem pouco valor. Além disso, o uso de novos conceitos deveria ser motivado por sua contribuição a novos conhecimentos, e o conceito de globalização deveria indicar a existência de algo novo nesse mundo.

U ma segunda resposta adequada implicaria em situar o conceito em discursos reais atuais e, a partir daí, talvez continuar a especificar as definições individuais. Desde o final da década de 80 , a noção de globalização surgiu em, pelo menos, cinco tipos centrais de discurso.

0 principal deles é o econômico, que se refere a novos padrões de comércio, investimento, produção e empreendimento. Um segundo tipo, geralmente derivado do primeiro, é o sócio-político, concentrando-se no papel cada vez menor do estado e de um tipo de organização social a ele associada. Em terceiro lugar, a globalização surgiu como centro de um discurso e de um protesto sócio-críticos, como uma nova forma que assumem as forças adversas: 0 inimigo da justiça social e de valores culturais particulares. Há outros dois outros discursos, mais especializados, mas igualmente importantes. Existe 0 discurso cultural, dos estudos antropológicos e culturais, que apresenta a globalização como fluxos, encontros e hibridismo culturais. Por fim, como responsabilidade social, a globalização é parte de um discurso ecológico e de preocupações ambientais planetárias.

Cada um desses discursos tende a ser impulsionado por uma dinâmica própria, com pouca ou nenhuma ressonância nos outros.

U ma terceira resposta para a pergunta "O que é globalização?" seria a de caráter reflexivo, a qual pondera: a globalização está sendo concebida de diversas formas mas, para propósitos de análise social científica, entendo 
que esta é a mais proveitosa, pelas seguintes razões.

Considerando esse debate, podemos propor uma definição. Como conceito de teoria e análise social, globalização deve dar conta de três tipos de exigências: deve ter um significado preciso, de preferência nãoarbitrário do ponto de vista semântico; deve ser passível de uso em investigações empíricas e ter uma ampla possibilidade de aplicação; a terceira exigência é que o conceito deve ser abstrato, não contendo qualquer conteúdo concreto a priori. Com base nessas considerações, parece-me importante definir a globalização estando relacionada a tendências de alcance, impacto ou encadeamento globais dos fenômenos sociais, ou a uma consciência de abrangência mundial entre os atores sociais. Essa definição aproxima-se da etimologia da palavra, transformando o conceito em uma variável empírica, cuja presença pode ser verificada ou negada e, em princípio, medida. Além disso, ela é agnóstica e ampla com relação aos padrões concretos possíveis de globalização e não tem qualquer compromisso a priori com um caráter bom ou mau do fenômeno.

Mas a globalização é mais do que um conceito, ela é também um modo de enfocar a realidade ou uma perspectiva analítica e, em termos mais amplos, discursiva. Como tal, é utilizada em algumas das mais influentes visões de mundo, nas quais ela pode ser apreendida com o auxílio de duas dimensões. Uma delas, que podemos denominar como dimensionalidade, diz respeito a como o conteúdo atual da globalização é percebido, predominante, fundamental e basicamente, como sendo econômico, cultural ou ecológico ou, como irredutível, possível e contraditoriamente multifacetado. A outra pode ser chamada de historicidade. A globalização está sendo considerada como uma ruptura básica na história humana moderna e, alternativamente, sua forma corrente é vista como uma nova versão de um fenômeno histórico mais antigo, ou como a manifestação presente de processos permanentes de transformação social. 
Tabela 1: Visões da globalização

\begin{tabular}{c|l|l}
\hline Historicidade & \multicolumn{2}{|c}{ Dimensionalidade } \\
\hline \multirow{2}{*}{ Singularidade } & Unidimensional & Multidimensional \\
\cline { 2 - 3 } Recorrência & $\begin{array}{l}\text { 1. Rupturalistas } \\
\text { econômicos/culturais }\end{array}$ & $\begin{array}{l}\text { 2. Rupturalistas } \\
\text { sociológicos } \\
\text { econômicos }\end{array}$ \\
\hline
\end{tabular}

O bservação: Este layout foi inspirado em uma idéia semelhante apresentada por John Gooldhorpe, em outubro de 2000, em nossa oficina sobre processos globais de desigualdade.

Entre essas quatro principais posições sobre a globalização, a última apresenta-se mais promissora em termos cognitivos. Sua abordagem histórica nos leva a férteis comparações históricas, talvez mais visivelmente com a onda globalizante que se extende da segunda metade do Século XIX à Segunda Guerra M undial, mastambém a comparações com ondas anteriores, desde o estabelecimento das "religiões mundiais", a conquista das Américas, e assim por diante. Em lugar de ser definida de saída, a questão das proporções da ruptura que a onda atual acarreta é deixada em aberto, como questão empírica que é. É verdade que complexidade e circunspecção não são necessariamente uma virtude científica - as árvores podem escurecer a floresta - masuma ênfase na globalização de um tipo de fenômeno implica em perder de vista a ocorrência de processos globais distintos e conflitantes, como, por exemplo, do capitalismo, da cultura, da normatividade (direitos humanos).

Como variável, a globalização pode cobrir um número infinito de aspectos da vida social, isto é, pode variar em amplitude, de apenas multicontinental até rigorosamente planetária, e pode também ser movida por dinâmicas diferentes. Em suma, o conceito refere-se a uma pluralidade de processos sociais, e a palavra mais adequada aqui seria "globalizações", no plural. 
A multidimensionalidade da globalização pode ser ilustrada por um conjunto de variáveis sociais importantes, que considerei como uma bússola simplificada para atingir a sistematicidade em análise social comparativa (veja, por exemplo, Therborn, 1995). N este viés, a globalização poderá acarretar:

Processos globais de estruturação social, como a divisão do trabalho, a alocação de direitos, a distribuição de riqueza e renda. Ela também poderá incluir a padronização de riscos e oportunidades de acordo com a passagem do tempo, processos de assimilação cultural, de formação de identidades, de definições e distribuição de conhecimento, de constituição de valores e de instituição de normas, de construção e recepção de formas simbólicas. Em terceiro lugar, a globalização poderá envolver ação social, seja em alcance de sentido único ou de interação, de ação individual dispersa ou coletiva, de harmonia ou de conflito.

A dinâmica dessas globalizações pode ser considerada ou interativa ou sistêmica, desempenhada por atores moldados de forma exógena ou endógena, ou ainda como um misto de ambos (veja mais em Therborn, 2000a).

As globalizações atuais não são historicamente singulares, a não ser no sentido trivial de que qualquer evento pode ser considerado único. Com relação às tendências no sentido de um alcance ou impacto global, entendo que podemos identificar, pelo menos, seis grandes ondas históricas. A primeira delas é a difu são das religiões mundiais e o estabelecimento das civilizações transcontinentais, concentradas nos Séculos IV e VII dC. Todas as ondas, até hoje, esgotaram-se depois de algum tempo e foram seguidas por períodos mais longos ou mais curtos de desglobalização. Cada onda, porém, não foi seguida por ou originou outra, o que significa que 0 arrefecimento de uma pode coincidir, em termos de tempo, com o surgimento de outra. 
Não existe, até onde eu sei, qualquer evidência de algo que caracterize as ondas de globalização como cíclicas, mas elas tendem a ter algumas características em comum. Todas foram multidimensionais, envolvendo forças e processos político-militares, econômicos e culturais, cada uma com uma dinâmica dominante. Até hoje, o surgimento das ondas derivouse de atores autônomos ampliando sua influência e impacto, e não da intensificação de processos sistêmicos. M as cada uma delas inclinou-se a criar uma certa sistematicidade global, seja ela de uma cultura religiosa, um império, um mercado ou um sistema de conflito mundiais. Em momentos de enfraquecimento da onda, e ainda mais quando seguidos por uma fase de desglobalização, essa sistematicidade foi enfraquecida ou perdida (Therborn, 2000a). Em outras palavras, há poucas razões para se considerar a globalização como sendo o fim da linha da história social.

\section{(Des)igualdade do quê? Entre quem? De que forma?}

Vivemos tempos nos quais a igualdade não é um bem evidente por si só entre os desfavorecidos. O s partidários da igualdade têm de defender seu ponto de vista em relação à diversidade individual e cultural, bem como ao individualismo, à diferença, ao pluralismo, ao multiculturalismo e a um retorno do geneticismo. Não trataremos aqui da discussão ética como um todo, e o que segue parte de um axioma moral, do valor fundamentalmente igual de todos os seres humanos e de cada um deles enquanto tal. Não obstante, dado esse pressuposto ético do valor humano igual, e dado o fato empírico da imensa diversidade humana, quais são as desigualdades social e moralmente importantes?

Acredito que as melhores respostas a essa pergunta derivam da capacidade humana, de ações e funcionamentos e da viabilidade de planejamento social. 0 primeiro conceito foi desenvolvido por Amartya Sen (1992, 2000), como uma alternativa igualitária individualista ao utilitarismo, e tra- 
ta da desigualdade no que concerne à qualidade de vida, àquilo que uma pessoa é capaz de ser e fazer. 0 último não foi ainda explicitamente teorizado como um princípio, mas refere-se à capacidade cultural supragenética que os seres humanos têm para criar uma ampla gama de sociedades viáveis².

Nos campos teórico e ético, bem como no analítico, Amartya Sen (2000, p. 80) afirmou .... necessidade geral de liberar a análise da desigualdade econômica de seu confinamento ao espaço da renda ou da propriedade de mercadorias.

De acordo com a autora,

as funções das quais depende o florescimento da espécie humana incluem coisas tão elementares como estar vivo, bem nutrido e com boa saúde, poder circular livremente e assim por diante. Aqui podem ser incluídas funções mais complexas, como possuir auto-estima e respeito pelos outros, participar da vida da comunidade... (Sen 2000, p. 74).

As implicações práticas, tanto em termos de pesquisa como de política, da própria "abordagem de capacidades" de Sen ainda precisam ser melhor especificadas, embora ela tenha conseguido avançar da teoria social para as estatísticas internacionais, nos Relatórios de D esenvolvimento H umano da O NU e seu Índice de Desenvolvimento H umano. Este último é um composto de expectativa de vida, realizações educacionais (alfabetização somada à matrícula nos ensino secundário e superior) e (um valor descontado de) PIB per capita (em termos de paridade de poder de compra). A desigualdade crucial na perspectiva de Sen é a falta de liberdade, na forma de privações de capacidades.

2 No marxismo estrutural, a estrutura de classes e seu núcleo de exploração sempre foram o foco da desigualdade, claramente diferenciados de possibilidades individuais de mobilidade dentro de uma estrutura dada de posições. A "capacidade de organização da sociedade" é uma formulação da mesma idéia, mais orientada para políticas, fazendo uma alusão a uma recolocação recente da reestruturação variável da desigualdade. Claude Fischer et al., Inequality by Design. Cracking the Bell Curve Myth, Princeton, Princeton U niversity Press, 1996. 
Martha N ussbaum (2000) deu às capacidades de Sen uma base filosófica mais avançada e muito interessante, com referência em Marx e Aristóteles. A autora resume parte de seu argumento em uma lista de "capacidades humanas centrais" cuja distribuição constitui a demanda central da ética igualitária, proporcionando um ponto de referência para o exame da desigualdade global. Sua lista compreende:

Vida, com duração normal

Saúde física

Integridade física, com relação à agressão e às discriminaçõessexual ou reprodutiva

Sentidos, imaginação e pensamento, ou seja, ser capaz de utilizá-los de "uma forma verdadeiramente humana" Emoções, a capacidade de ter vínculos, a liberdade do medo e trauma opressivos

A razão prática, ou seja, ser capaz de estabelecer concepções sobre o bem

Vínculos, incluindo as bases sociais do respeito próprio e da não-humilhação

O utras espécies, ser capaz de viver com preocupaçõescom relação à natureza

O lúdico, ser capaz de rir, brincar e recriar-se

0 controle sobre seu próprio ambiente, político e material (Nussbaum, 2000, pp. 78-80).

A partir das pesquisas suecas e escandinavas sobre o padrão de vida (Swedish and Scandinavian Level of Living Surveys), também se pode produzir uma lista empiricamente manejável de (des)igualdades, com dez componentes: nutrição, saúde e acesso aos serviços de saúde, emprego e condições de trabalho, recursos econômicos, conhecimento e acesso à educação, relações familiares e sociais, habitação e serviços locais, recreação e cultura, segurança da vida e da propriedade, recursos políticos. 
0 que queremos destacar aqui, como conclusão da nova abordagem de capacidades, é a multidimensionalidade fundamental da desigualdade básica. Da mesma forma que pouco se pode reduzir a globalização ao comércio e aos fluxos de capital do mundo, os processos globais da (des)igualdade são irredutíveis às distribuições do PIB nacional per capita ou da renda individual ou familiar, independentemente de sua importância.

A desigualdade nas capacidades, ou nas oportunidades de vida, para utilizar um conceito clássico, podem ser consideradas como uma soma de recursos e ambientes. Ambos são pertinentes à capacidade de conquistar feitos e realizações às quais se tenha motivos para dar valor. M as, enquanto os recursos podem ser distribuíd os individualmente, os ambientes indicam a ausência ou presença de contextos de acesso e de possibilidades de escolha.

\section{Desigualdade entre quem?}

Todos os discursos sobre desigualdade referem-se à diferença no interior de uma determinada categoria de pessoas. Isso é importante porque a categoria pertinente é variável e, na verdade, transformou-se no tempo e no espaço. Há muito é evidente a desigualdade entre grupos descendentes, famílias, linhagens, raças e entre grupos profissionais amplos, castas, estamentos, classes. Já as desigualdades entre nações, gêneros, grupos etários, regiões e entre a humanidade como todo, receberam interesse público muito mais recentemente. Apenas um número relativamente pequeno entre uma quantidade praticamente sem limites de desigualdades potenciais ganhou relevância. É o caso da cor da pele, mas raramente da cor dos olhos ou do cabelo; e de descendentes de grupos étnicos, mas raramente de grupos territoriais, como os oriundos de diferentes províncias ou cidades. A desigualdade entre distintas profissões costuma ser considerada importante, mas raramente entre pessoas com um mesmo aniver- 
sário, digamos, os nascidos em 1940 e em 1946. 0 mesmo acontece com amplos grupos etários e gerações, mas não entre quem tem 37 anos e quem tem 39. Entretanto, o número de categorias de comparação freqüentemente utilizadas tornou-se amplo o suficiente para gerar concorrência pela atenção.

A globalização implica, obviamente, em que a desigualdade entre a humanidade global esteja recebendo mais atenção. Somente com 0 desenvolvimentismo pós-Segunda Guerra Mundial, a desigualdade entre as nações do mundo recebeu atenção pública. $A$ atual onda de globalização está provocando a comparação entre outras categorias humanas, como as mulheres do mundo, as crianças do mundo, domicílios em todo planeta.

No entanto, há outras questões importantes. O s indivíduos e os domicílios são partes de comunidades - definidas étnica, religiosa, territorialmente, ou de outra forma - e a igualdade intercomunidades é uma parte importante da concepção de justiça de muitas pessoas, embora seja muitas vezes negligenciada na literatura internacional acadêmica e sobre políticas (Kanbur, 2000, p. 825). Por outro lado, a igualdade intrafamiliar, especialmente entre meninos e meninas, homens e mulheres, recebe cada vez mais atenção internacional.

Preocupar-se com a desigualdade, em vez de apenas com a pobreza, significa preocupar-se com a maneira como toda a sociedade é estruturada e não apenas com o seu pior aspecto ${ }^{3}$. Assim sendo, a preocupação com a desigualdade é mais propícia à auto-organização e mobilização dos próprios desfavorecidos, ao conflito social e à transformação social em grande escala do que a preocupação com a pobreza, pois esta tem uma orientação mais

\footnotetext{
3 É necessário enfatizar que o reconhecimento crescente da questão da pobreza por parte de instituições internacionais não equivale a uma preocupação com a desigualdade e com o tecido social na condição de ambiente humano. 0 Chile durante a ditadura de Pinochet era, em muitos aspectos, uma referência internacional do neolineralismo, e o tratamento dado pelo regime à crise econômica de 1982-84 é um exemplo. As políticas do governo favoreceram os 10\% mais ricos, o que não é uma surpresa. Salvar essas pessoas de seu próprio endividamento custou cerca de $5 \%$ do PIB, ao mesmo tempo, os subsídios à alimentação também ajudaram os $10 \%$ mais pobres. 0 s grandes perdedores foram os desempregados e outros grupos situados no segundo e terceiros décimos. (Bourguignon and Morrisson 1992:43). A desigualdade no país saltou de um índice Gini de 53 em 1980 para 59 em 1989 (Londoño and Székely 1997, p. 40).
} 
naturalmente filantrópica. Na política igualitária, pode ser mais fácil voltar-se basicamente para a desigualdade dos ricos, como um alvo da crítica social. Entretanto, de uma perspectiva igualitária moral, pode-se sustentar que a desigualdade dos pobres é a mais relevante, isto é, a tarefa mais importante para a mudança, já que tende a excluí-los da participação integral na sociedade dominante. Se concordarmos com esse argumento, há implicações analíticas, pois as medidas da pobreza relativa passam a ser particularmente pertinentes, como medidas de desigualdade. Em nível nacional, isso costuma ser avaliado atualmente através da proporção da população que tem uma renda disponível abaixo da metade da média nacional. Às vezes, também é medido pela taxa de renda média em relação à do nono percentil. Embora tendam a estar muito relacionadas, a desigualdade dos ricose a dos pobres podem variar independentemente uma da outra. A desigualdade extraordinária da América Latina é, acima de tudo, uma desigualdade dos $30 \%$ mais pobres, que recebem (relativamente) menos do que seus pares na África ou em outro lugar, mas também é, especialmente em países como Chile e o México, uma desigualdade dos $10 \%$ mais privilegiados (Banco Interamericano de Desenvolvimento, 1998, pp. 11,16).

\section{Formas sociais de desigualdade}

Além disso, a questão "desigualdade do quê?" não deve ser considerada apenas como ponto de partida para reflexões éticas sobre justiça e liberdade. Esta é também uma questão empírica, de organização social, ou seja: "Q uais as formas de desigualdade que estamos enfrentando?" Podemos chamar a isso de modo de produção de valor, referindo-nos aos processo de definição de recursos e ambientes valiosos e da definição dos padrões de sua geração.

O número de realizações ou propriedades consideradas de alto valor e o grau no qual os valores são conversíveis uns aos outros, são 
questões fundamentais relacionadas ao modo de produção de valores. Se houver um valor supremo, digamos, o dinheiro, ou se o dinheiro e to dos os outros valores altos forem facilmente conversíveis uns aos outros, teremos uma forma de desigualdade, uma escada monetária vertical. Se houver mais valores altos que sejam difíceis de transformar uns nos outros, teremos um outro conjunto de formas de desigualdades, tais como, por exemplo, os quatro quadrantes de riqueza econômica, riqueza cultural, pobreza econômica e pobreza cultural de Pierre Bourdieu (1979).

Seriam os valores fundamentais que desejamos produzidos para alguns através de sua extração de outros? Q ual a importância das classificações de inferioridade e superioridade? São estas mais ou menos importantes do que os limites de categoria entre os que estão dentro e os que estão fora? Estará a desigualdade concentrada em algum limite específico ou existe um conjunto múltiplo de demarcações? Estes limites se dão basicamente entre aqueles que pertencem e aqueles que não pertencem, independentemente de suas vontades, ou funcionam em termos de escolha e interesse? As respostas para essas questões e outras semelhantes tornam possível a distinção entre formas diferentes de desigualdade. Podemos resumir as formas básicas em uma tabela.

Tabela 2: Formas básicas de desigualdade

\begin{tabular}{l|l|l}
\hline \multirow{2}{*}{ Limites Territoriais } & \multicolumn{2}{|l}{ Ordenamento Básico } \\
\cline { 2 - 3 } & $\begin{array}{l}\text { Vertical } \\
\text { (Alto/Baixo) }\end{array}$ & $\begin{array}{l}\text { H orizontal } \\
\text { (D entro/Fora) }\end{array}$ \\
\hline Único (M onopólio) & Exploração & Exclusão \\
\hline Múltiplo (Diferenciação) & Hierarquia & Segmentação \\
\hline
\end{tabular}

Cada uma dessas formas ou configurações varia quantitativamente em seu montante específico de desigualdade, ou seja, no grau de fechamento ou porosidade de seus limites, na quantidade de extração 
exploratória, na magnitude relativa de membros do grupo e de estranhos excluídos, na extensão da escada hierárquica e na disposição de seus degraus e no número de segmentos separados entre uma população dada.

A exploração é uma dessas formas (veja mais em Tilly:98). Trata-se de uma divisão categórica entre pessoas superiores e inferiores, onde estes devem produzir valores para aqueles, ou onde os mais fortes extraem uma quantidade injusta de valor dos mais fracos, segundo algum padrão de referência (Miller, 1999, pp. 204-5). As relações coloniais em geral, e as variações específicas, como a escravidão das plantations ou o apartheid, exemplificam particularmente esse tipo de desigualdade. Muitos sistemas familiares foram construídos, em grande parte,. sobre a exploração das mulheres pelos homens.

0 mundo pós-colonial tem-se inclinado mais à hierarquia do que à exploração colonial em uma escada classificatória da conquista desigual de valores, em grande parte, comuns. Em escala global, os contornos gerais de desenvolvimento no Século XX, acentuados em seu final, parecem ser uma definição convergente de valores, certamente incompleta, com uma capacidade predominantemente, se não totalmente, divergente de geração desses valores. Isso significa que o consumo individual de bens tornou-se um valor básico muito mais comum no mundo, com o encolhimento de formas de vida rurais definidas localmente, com a erosão de autoridades tradicionais e modelos de virtude e sabedoria, e com o recente colapso ou, no caso do Leste da Ásia, transformação radical do comunismo. Em outras palavras, com o declínio de tradições e o desaparecimento de modernidades alternativas. Este padrão global de valores de consumo convergentes e possibilidades de consumo divergentes traz em si o potencial para explosões sociais.

A exclusão categórica funcionou historicamente com muitos critérios diferentes, entre os principais, o sexo, a etnia/raça, a idade e a propriedade. Na segunda metade do Século XX houve uma erosão importante nas exclusões baseadas em sexo, raça e idade. A complexidade da organiza- 
ção econômica contemporânea tornou mais indefinida a divisão entre os quem têm e os que não têm. Se, por um lado, nenhuma dessas divisões categóricas desapareceu como limite de exclusão, pode-se afirmar que a cidadania, ou, mais precisamente, o direito legal de residência em um determinado território, tornou-se uma forma importante de exclusão, dividindo forasteiros e residentes. Esta divisão assume proporções significativas frente a um mundo cada vez mais hierárquico e hierarquicamente interconectado. A importância da divisão baseada no direito legal de residência em um Estado-N ação ou outro e o seu fortalecimento através de políticas nacionais de desenvolvimento e redistribuição estão em contradição com o crescimento da comunicação global e a diminuição dos custos de transporte. As migrações entre nações tornaram-se questões altamente controversas em todos os continentes.

A segmentação é ainda mais uma forma de desigualdade, antes horizontal do que vertical, e não necessariamente exige qualquer limite categórico. Tanto o multiculturalismo quanto a diferenciação de estilos de vida podem funcionar através da segmentação. As políticas de identidade podem ser segmentadas, bem como excludentes.

Os exemplos e hipóteses rápida e cruamente delineados que aqui apresentamos não são o ponto principal de nossa argumentação. Mais importante é saber que não existem apenas diferentes quantidades de desigualdade em relação a esta ou aquela variável. Há também diferente configurações de desigualdade, que operam de maneiras diferenciadas.

\section{Conseqüências globais, processos globais e outros}

Não há dúvida de que este mundo é muito desigual. As conseqüências globais do PIB per capita, da renda familiar, da renda por gênero, das expectativas de vida nacional, por classe e por gênero, da educação nacional, por classe e por gênero e assim por diante, são muito desiguais. No 
que diz respeito a um grande número de recursos, ambientes e perspectivas, podem se elaborar classificações de vantagens e desvantagens ${ }^{4}$.

Se essas conseqüências globais seriam ou não o resultado de processos globais é uma outra questão. Em princípio, elas também poderiam ser resultado de processos locais ou nacionais. Se eu disputasse uma corrida contra uma equipe de atletas globais, com certeza chegaria em último, mas isso seria resultado de minha própria trajetória de vida, como um acadêmico não-atleta, e não de qualquer processo relacionado ao atletismo global.

\section{Como explicar as desigualdades globais?}

Como podemos chegar aos determinantes dos resultados distributivos globais? Parece-me que para compreender a questão devemos começar com o estado-nação e a economia e sociedade nele baseadas, como determinante básico dos níveis de vida do povo. Nesse sentido, a nação não é, de forma alguma, um sistema fechado, e sua primazia pode muito bem estar sendo desgastada e substituída como determinante do nível de vida por certas categorias sociais. Mas ela parece ser a base mais adequada para construção de uma cadeia causal. As fronteiras da cidadania e, mais ainda, do direito legal de residência afetam de forma crucial as oportunidades de vida da maioria das pessoas. As relações sociais econômicas e não-econômicas são definidas em muito pelas economias e sociedades baseadas no estado. O Estado-Nação atual tem uma grande capacidade de alocação e redistribuição de recursos, e controla diretamente de um a dois terços de todo o PIB da maioria dos países desenvolvidos.

A globalidade afeta essa determinação das capabilidades humanas a partir de três ângulos: 0 da história, o da amplitude e o do entrelaçamento globais.

4 Em um artigo paralelo a este, aplico os dez componentes dos estudos suecos sobre o nível de vida à situação global. Um esboço chamado Global Processes of Inequality foi apresentado em uma conferência em Saltsjöbaden, perto de Estocolmo, em outubro de 2000 . 
As populações, culturas e vínculos de todos os estados-nação e economias e sociedades nacionais atuais foram definidos por forças e processos extra-nacionais. A história global tem uma importância muito grande sobre todos eles, e é aqui que entra a análise de sistemas mundiais e dos diferentes caminhos até a modernidade. Entretanto, em um caminho ou outro, e de uma forma ou outra, esta história global levou a sistemas sociais baseados no estado, com propriedades e dinâmicas políticas, econômicas, sociais e culturais próprias, incluindo capacidades específicas para fazer uso de sua localização no mundo. E essa dinâmica conforma os processos nacionais de alocação e distribuição.

Em sua atual forma de funcionamento no mundo, as ações são afetadas por dois tipos de processos globais permanentes. Mais visíveis são os fluxos globais, ou pelo menos trans-nacionais, de bens e serviços, de capital, de populações, mas também devem ser lembrados os fluxos de conhecimento e idéias. Esses fluxos têm uma dinâmica geral característica própria, a qual é intrinsecamente a mesma, qualquer que seja a sua extensão: local, nacional, regional ou global As dinâmicas de mercado do comércio e das finanças, a circulação nas cadeias migratóriase a difusão do conhecimento, (todas) têm efeitos distributivos diretos, mas também podem ser acompanhados em seus efeitos sobre as economias, sociedades e estados nacionais, incluindo os efeitos sobre a capacidade redistributiva destes últimos.

Existe um segundo processo global que podemos chamar de entrelaçamento global, e que diz respeito à imbricação de instituições, ao envolvimento de diferentes conjuntos de atores, nacionais e globais, locais e globais. A forma mais tangível deste entrelaçamento é a emergência de organizações globais muito ativas, que interagem com governos, políticos e movimentos nacionais e locais, e sobre eles têm influência. Os mais poderosos são o Banco M undial e o FMI, mas também há as organizações da O NU, entre as quais a OMS, a Unicef, a FAO, a ILO e a Unesco são as mais importantes. Entre os países ricos, a O ECD tem sua importância, na Europa, a U nião Européia e o Conselho da Europa, e globalmente, alinha- 
mentos com as superpotências, muito importantes no perío do da guerra fria. O s bancos regionais de desenvolvimento, embora sejam relativamente marginais, não devem deixar de ser considerados.

Podemos apresentar a produção da desigualdade global - e da desigualdade que existe no mundo - em uma simples figura.

Fluxos Globais:

de Bens, Capital, Populações, Conhecimento

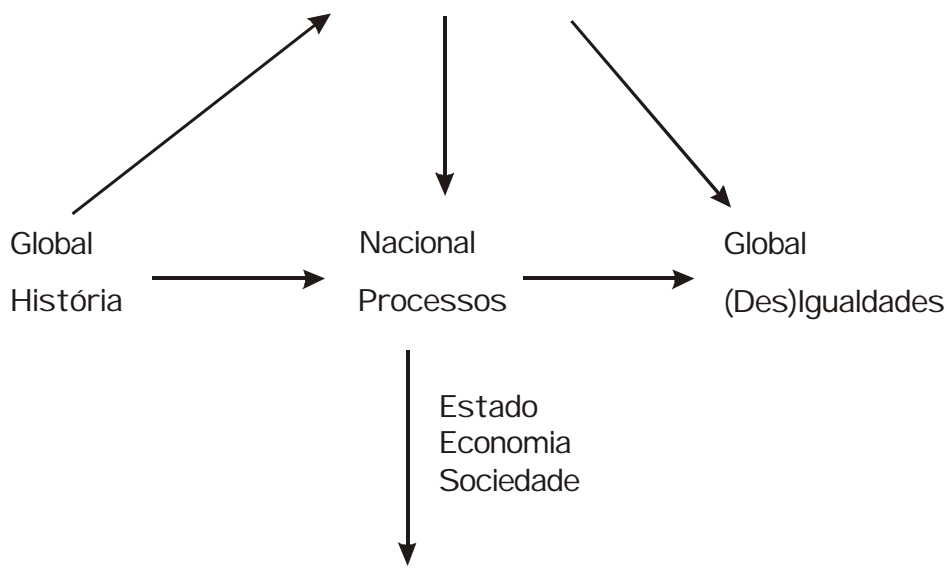

Global Entanglements

Do Nacional e do Global

Do Local e do Global

Figura 1. Determinantes das (des)igualdades globais.

0 próximo passo nesta abordagem da difícil questão de como explicar a desigualdade global seria elaborar um primeiro ordenamento dos conjuntos de variáveis explicativas, com relação à sua importância provável para os diferentes tipos de desigualdade. Para que isso não seja complicado demais já no início, concentremo-nos aqui sobre as desigualdades vital (expectativa de vida) e de renda. 
0 peso da história

A maioria dos Estados- $N$ ação de hoje em dia deve sua origem a forças variáveis externas transoceânicas intercontinentais: é o caso da totalidade das Américas e praticamente toda a África e a Ásia, com algumas poucas exceções parciais, das quais as mais significativas são a China e 0 Japão. Já são bem conhecidos os efeitos traumáticos e duráveis da destruição social das conquistas coloniais, da exploração colonial e étnica - características tanto das principais áreas da América hispânica e das colônias dos Séculos XIX e XX, mas não das colonizações genocidas da América do norte, da parte sul das Américas e da Austrália - e da escravidão das plantations? É verdade que seus traços são muitas vezes apagados da memória entre os seus beneficiários, os quais, a partir de suas bases no atlântico norte e no litoral nordeste do pacífico estão dominando a ciência social contemporânea ${ }^{5}$.

O legado histórico também poderia ser analisado em termos dos diferentes caminhos para a modernidade, o europeu endógeno (materializado, acima de tudo, no noroeste da Europa), os novos mundos coloniais, diferenciados pelo genocídio e pela atitude colonial dos próprios colonos, a Zona Colonial e os países subdesenvolvidos da Modernização Reativa (Therborn, 1999). Essa postura abre caminhos para a investigação comparativa das origens e das características regionais contemporâneas, como a extraordinária desigualdade da América latina (ex-colonial, não-genocida), o elitismo particular da educação do sul da Ásia ou a divisão entre as sociedades urbana e rural específica da África, e a tendência africana excepcionalmente forte no sentido de estados predatórios.

Mas, para avaliar a importância da história sobre os padrões contemporâneos de distribuição, é preciso que sejamos mais sistemáticos. U ma possibilidade de abordagem, assim, pode ser a observação do Século XX com relação

5 Com relação aos mecanismos básicos utilizados aqui, veja Tilly, 1998, sobre exploração absoluta, e Paterson, 1998, sobre os efeitos duradouros da escravidão dasplantations. 
a alguns aspectos específicos da desigualdade. 0 ptemos aqui pela desigualdade vital e econômica. Q uanto mais os resultados distributivos globais em 2000 lembram os de 1900, mais influência a história teve sobre eles.

O s quadros com os cálculos da expectativa de vida no momento do nascimento não têm dados muito antigos em alguns países, mas temos séries mais longas de taxas de mortalidade infantil, um componente decisivo da expectativa de vida no momento do nascimento, embora, como todos os dados históricos, sujeitos a uma determinada margem de erro.

Q uadro 1: Taxas Relativas de M ortalidade 1900-1999. Países Selecionados

\begin{tabular}{|l|c|c|c|}
\hline & 1900 & 1950 & 1999 \\
\hline França & $(162=) 0$ & $(52=) 0$ & $(6=) 0$ \\
\hline Espanha & 52 & 12 & 1 \\
\hline Rússia & 90 & 29 & 12 \\
\hline EUA & -19 & -13 & 1 \\
\hline Argentina & $22(\mathrm{a})$ & 16 & 16 \\
\hline México & $180(\mathrm{~b})$ & 44 & 25 \\
\hline Egito & $53(\mathrm{c})$ & 78 & 45 \\
\hline Índia & $83(\mathrm{~d})$ & 85 & 66 \\
\hline Japão & $64(\mathrm{a})$ & 8 & -2 \\
\hline Sri Lanka & $32(\mathrm{e})$ & 30 & 12 \\
\hline
\end{tabular}

Taxas relativas, distância de um padrão de referência, França, para cada ano=0 Fontes: J.-C. Chesnais, The demographic transition. O xford Clarendon Press, 1992, tabelas A4.2-5; ONU, The state of the world population, edição na internet, 2000. Notas: Todos os seguintes períodos são comparados com a França no mesmo intervalo: a. 1920-25; b. 1900; c. 1920; d. 1910; e. 1901-05.

Correlações: 1900-1950: 0.52; 1900-1999 0.39; 1950-1999 0.95 
No decorrer do Século XX, a mortalidade infantil tornou-se menos desigual no mundo, e com ela, a expectativa de vida. No início do século (a escassez e falta de confiabilidade da maioria dos dados referentes ao terceiro mundo torna necessário fazer comparações entre décadas) o total da diferença global entre nove países, nas proporções de mortes em relação à França, representante da Europa ocidental, era de 597 para cada 1000 pontos; em 1950, era 305 e em 1999, de 180. 0 desvio padrão passou de 55,5 para 21,9, via 32,1.

Os movimentos relativos foram limitados, e as origens históricas pesaram muito no destino relativo das crianças no século recém-terminado. 0 sul da Europa, aqui representado pela Espanha, e o Japão, conseguiram recuperar-se e chegaram ao topo; os Estados U nidos perderam a liderança e o México teve mais sucesso do que muitos outros países do terceiro mundo, embora deva-se observar que o número referente ao Egito na tabela é da década de 20, sendo provavelmente muito mais alto em 1900. Além disso, a grande distância do M éxico em relação à Índia no início do século não é segura, embora outras séries cronológicas indiquem que a taxa de mortalidade geral no $M$ éxico nas décadas de 20 e 30 era mais alta do que a da Índia. 0 declínio absoluto depois da Segunda Guerra M undial ocorreu em períod os históricos diferenciados. Os dados de 1950 antecipam corretamente $90 \%$ daqueles referentes a 1999.

0 peso da história vale também, sem dúvida, para os desenvolvimentos globais de renda, e a este respeito historiadores econômicos têm feito muito mais estimativas que demógrafos históricos. 
Q uadro 2: PIB Relativo per capita no mundo 1820-1999

Índice: Estados U nidos a cada ano $=100$.

\begin{tabular}{|l|c|c|c|c|}
\hline & 1820 & 1900 & 1950 & 1999 \\
\hline Europa O cidental(a) & 95 & 71 & 58 & 76 \\
\hline França & 95 & 70 & 55 & 72 \\
\hline Espanha & 83 & 50 & 25 & 55 \\
\hline Rússia & 58 & 30 & 30 & 21 \\
\hline Turquia &.. & $18(\mathrm{~b})$ & 14 & 20 \\
\hline América Latina(c) &.. & 32 & 36 & 23 \\
\hline Argentina &.. & 67 & 52 & 37 \\
\hline Brasil & 52 & 17 & 17 & 21 \\
\hline México & 59 & 28 & 22 & 25 \\
\hline China & 40 & 16 & 6 & 11 \\
\hline Índia & 41 & 15 & 6 & 7 \\
\hline Indonésia & 48 & 18 & 9 & 8 \\
\hline Japão & 55 & 28 & 20 & 79 \\
\hline Coréia do Sul &.. & 21 & 9 & 48 \\
\hline Tailândia &.. & 20 & 9 & 18 \\
\hline Egito &.. & 12 & 5 & 11 \\
\hline Gana &. & 11 & 12 & 6 \\
\hline Nigéria &. & 13 & 2 \\
\hline
\end{tabular}

Fontes: cálculos de 1820-1950: A. Maddison, Monitoring the world economy 18201992. Paris: OECD, 1995, tabela 1-3; 1999: Banco Mundial, World Development Report 2000/2001. Nova lorque: OUP, 2000, tabela 1.

Notas: a. Médias aritméticas da Áustria, Bélgica, Dinamarca, Finlândia, França, Alemanha, Itália, Holanda, Noruega, Suécia, Suíça e Reino unido, isto é, uma definição econômica de "Europa ocidental" de meados do século XX. b. 1913, comparado com os Estados Unidos no mesmo período. c. Médias aritméticas de Argentina, Brasil, Chile, Colômbia, México, Peru e Venezuela.

Correlações: 1820-1900:0.96; 1820-1950:0.89; 1820-1999:0.85; 1900-1950:0.96; 1900-1999:0.82; 1950-1999:0.77. 
A história global permanece muito presente entre nós. As regiões mais ricas do mundo no início do Século XXI são as mesmas da década de 1820, a América do Norte anglo-saxônica e o noroeste e o sul da Europa, nessa ordem. 0 Japão é o único país a entrar para o clube dos ricos na segunda metade do Século XX6 . O Século XIX assistiu ao surgimento espetacular dos Novos M undos de colonização européia, incluindo a Argentina, e a ainda mais espetacular estagnação da Ásia, enquanto a Europa dava um salto adiante, depois de estender suas ramificações para alémmar. Observe-se que o Japão era parte da decadência relativa da Ásia, embora em grau menor do que a China e a Índia. As outras histórias de sucesso do final do Século XX também se mantiveram, em 1910, em uma situação melhor do que os dois centros clássicos das civilizações do Sul e do Leste Asiáticos. A América Latina Indígena e Africana (no original indocreole and afro-creole) também perdeu no Século XIX. A África anterior a 1910 desafiou até mesmo os esforços históricos de Angus M addison, mas o continente era visivelmente muito pobre em 1900, e a África Sub-Saariana estava claramente empobrecida na segunda metade do século. A cronologia acima não faz justiça aos efeitos do comunismo na Rússia, pois apesar de esta ter sido vítima de guerras devastadoras, houve uma certa recuperação econômica. Em 1913, o PIB per capita russo era de $28 \%$ do dos EUA, em 1973, de 36\% (Maddison, 1995 loc. cit).

Houve, com certeza, movimentações nacionais no Século XX. Inglaterra e Argentina decaíram muito, assim como a África Sub-Saariana, ao passo que a Finlândia e a Coréia subiram, da mesma forma que o Japão. A China e outros países asiáticos estão se recuperando atualmente. A recente recuperação do leste da Ásia é responsável pelo fato de que a correlação histórica mais fraca entre PIBs é aquela entre 1951 e 1999. Entretanto, como um todo, ainda vivemos em um padrão de renda global estabelecido no Século 18 e no início do Século XIX; nossos dados da década de

6 Tirando-se, é claro, alguns minúsculos países governados por xeques, como o Kuwait e o Q atar, e a cidade-estado/entreposto de Cingapura. 
1820 conseguem antecipar corretamente $72 \%$ da situação de 1999 e, com os números de 1910 , podemos prever $67 \%$ do padrão existente um século mais tarde. Padrão este que coloca a Europa 0 cidental e suas colônias nos novos mundos no topo, as antigas zonas coloniais da África e da Europa na base e os países não-colonizados da M odernização Reativa e algumas misturas de povoação e colonialismo, como a maioria da América Latina, na posição intermediária, mas com uma vantagem significativa, no final do Século XX, da região da Ásia da M odernidade Reativa. A dispersão aumentou, com um desvio padrão de 2,8 em 1900, para 29,3 em 1999.

\section{A força dos fluxos}

A história não se reproduz por conta própria, isso é certo. As localizações históricas dos países na distribuição global foram reproduzidas pelos fluxos e entrelaçamentos transnacionais e por processos nacionais. Há várias maneiras para que se mantenham as vantagens iniciais, de qualquer origem, e que haja acumulação com o passar do tempo. Uma vez que uma economia tenha atingido um certo nível, haja "decolado", ela poderá sustentar uma alta taxa de poupança e investimento. Pais mais saudáveis, bem nutridos e bem educados tendem a produzir filhos semelhantes. U ma boa situação econômica tem mais probabilidades do que uma pobre de gerar e manter estabilidade política, e esta, por sua vez, mais chances de disseminar investimento e produção do que conflito social.

O s geógrafos econômicos têm observado, há muito tempo, ainda perplexos, a grande concentração de atividades econômicas especializadas em certas partes de um país sem qualquer vantagem natural. Na segunda metade do Século XX, essa idéia foi assumida e elaborada por algunseconomistas internacionais, gerando e, no estilo dos economistas, modelando processos dinâmicos de polarização econômica (Krugman, 1993; Krugman and Venables, 1995). D emonstrou-se que cada vez mais o retorno às economias de escala, 
a diminuição nos custos de transporte e a dependência cada vez menor dos recursos naturais fixos geram vantagens em um extremo e desvantagens em outro. A distinção centro-peripheria de Krugman pode ser considerada de certa forma como uma especificação da diferenciação anterior, feita por Immanuel W allerstein (1974) entre o centro e a periferia do moderno sistema mundial. Seria de se esperar que o mesmo tipo de processo estivesse na base da concentração da ciência e do saber erudito em algumas poucas instituições de elite. Resumindo, boa parte da influência da história consiste em espirais de causação virtuosas ou viciosas.

O comércio, os movimentos de capital e a migração são os fluxos econômicos clássicos. Com modelos comerciais mais sofisticados, e com uma atenção simultânea recente a todosos três fluxos, o impacto distributivo complexo e ambíguo desses fluxos está sendo cada vez mais reconhecido. Além disso, o tema tem-se tornado objeto de acirrada controvérsia. U m não-economista deveria ficar fora dessas águas profundas. Contudo, alguns padrões empíricos estão emergindo, assim como uma nova agenda de pesquisa.

No mundo real, o comércio internacional não costuma ter o efeito convergente teorizado e observado na região do Atlântico Norte por economistas e historiadores econômicos liberais escandinavos, como W icksell, Heckscher, and O hlin. Enquanto as economias latino-americanas e protecionistas, baseadas na substituição de importações, por exemplo, convergiam (em PIB) da depressão ao início da década de 80, as economias asiáticas voltadas para exportação, na verdade, divergiam, de 1960 até 1989 (Rodríguez and Rodrik 2000, p. 52). Grande parte da convergência econômica entre países da U nião Européia aconteceu antes que eles entrassem para o bloco. A partir daí a convergência arrefeceu (Therborn 1995, pp. 196-7). 0 efeito de curto prazo da abertura ao comércio e à concorrência internacionais é alvo de grandes polêmicas, à medida em que a globalização comercial é fortemente impulsionada por organizações internacionais como o Banco M undial. Na rodada daquele debate que aconte- 
ceu em Estocolmo, em outubro de 2000, Dani Rodrik (2000) desmontou de forma efetiva a afirmação de David Dollar e Art Kraay (2000), de que as economias "globalizantes" dos anos 80 tiveram uma taxa mais alta de crescimento em função de sua abertura. Não controverso, por outro lado, foi o fato de estes estudiosos não encontrarem qualquer correlação significativa entre o tamanho do comércio internacional e a desigualdade doméstica 0 que significa que, em alguns casos, como no sudeste da Ásia, a abertura tem pouco ou nenhum efeito polarizador, enquanto que um efeito posterior é visto em vários países da América Latina, (cf. W ood 1997; World Bank 2000a, pp. 70-71).

Em um grande estudo sobre as economias do Atlântico, Kevin 0 'Rourke and Jeffrey W illiamson (1999) fizeram uma análise comparativa de bens, capital e populações. Sua principal variável dependente foram os salários reais de 1870 a 1910, e sua principal conclusão foi a de que o fator mobilidade era responsável por grande parte da convergência. Acima de tudo, a migração massiva da Europa para o Novo mundo diminuiu as diferenças salariais de um lado ao outro do Atlântico; o afluxo de capital para a Escandinávia também foi importante e o comércio, por sua vez, teve um efeito menor ou, em alguns casos, nulo.

A importância do surgimento de uma agenda de pesquisa, então, seria juntar o comércio, com a mobilidade de trabalho e capital para a análise dos atuais fluxos globais. Esses fluxos mudaram recentemente de direção, afastando-se substancialmente dos padrões que, durante o final do Século XIX e a maioria do XX, reproduziram o mapa econômico mundial da primeira metade do Século XIX.

A onda de globalização do final do Século XIX criou, acima de tudo, um fluxo de vantagens mútuas entre as novas economias ricas. A Europa exportava grande parte de sua população - cerca de 60 milhões - para colônias despovoadas, ricas em terra e recursos, mas pobres em capital. Embora tenha havido outras migrações neste período, e as mais importantes foram as dispersões dos chineses no sudeste da Ásia, a dos europeus para a Améri- 
ca foi a predominante. O s fluxos de capital do principal investidor do mundo, a Inglaterra, também foram principalmente nessa direção, ao passo que os capitais franceses e alemães foram direcionados, em primeiro lugar, para a Europa do Leste. 0 padrão comercial era predominantemente industrial-agrário/minerador, com a Europa industrial exportando manufaturase importando comida e matérias-primas para a indústria, do N ovo Mundo e da Europa do Leste. 0 s impérios coloniais e seus fluxos internos estiveram à margem desse processo (cf. Hobsbawm, 1987, pp. 73-4).

A Primeira Guerra Mundial foi seguida de duas décadas de desglobalização, com o comércio, a migração e a mobilidade de capital em contração, e por outra guerra mundial. A reconstrução gradual de uma economia globalizada posterior à Segunda Guerra aconteceu em circunstâncias novas, tais como o surgimento das URSS como superpotência global, liderando um bloco comunista, a participação integral do Japão no círculo de países desenvolvidos, a onda de avanço de toda a Europa ocidental e a descolonização em escala mundial. Entretanto, em termos gerais, a ligação anterior a 1914 entre a Europa ocidental e economias coloniais do Novo mundo europeu, em fluxos de capital (agora basicamente dos Estados U nidos para a Europa O cidental), populações e comércio foi restabelecida, em um nível inferior de integração.

A primeira grande transformação do padrão dos fluxos foi a passagem da Europa, da condição de continente de emigrantes para um local de imigrantes, no início da década de 60. A Turquia, o norte da África e 0 sul da Ásia (para o Reino U nido) foram grandesfornecedores, seguidosnos anos 90, pela Europa do Leste. $\mathrm{Na}$ década de 1980, a imigração para os Estados Unidos começou a ganhar força novamente, mas não mais alimentada pela Europa. A América Latina passou de destino para fonte de migração. A discriminação racista foi eliminada da América do Norte e, mais tarde, na década de 70, da política de imigração australiana, abrindose para uma grande quantidade de imigração asiática. Resumindo, o clássico fluxo de migração do Atlântico Norte foi substituído por um fluxo sulnorte, embora de proporções menores do que o anterior. 
Este novo padrão migratório teria efeitos na produção de igualdade global, assim como o novo centro de migração do Golfo Pérsico e os sistemas regionais de migração do Sul e O este da África e Sudeste da Ásia, ainda que de tamanho modesto. Até o momento, parece haver pouco conhecimento sistemático sobre estes efeitos. O s números envolvidos costumam ser substanciais; oito por cento da população nascida no M éxico estava morando nos Estados U nidos na década de 90 , e cerca de $10 \%$ dos filipinos vivem no exterior. Nas nações menores do Caribe, a diáspora chega a 10 a 15\% da população (Binational Study on Migration 1998; Castles 2000; International O ffice of Migration 2000).

0 movimento de capital ainda acontece, em grande parte, entre a América do norte e Europa ocidental, representando algo entre 3/5 e 2/3 de todos os fluxos de investimento estrangeiro direto. Mas um aumento de investimento estrangeiro direto na última década do Século $X X$ representou o que pode ser o começo de um novo padrão, com uma parte mais importante indo para os países em desenvolvimento. A mudança deveu-se principalmente à emergência da China como um ponto de atração de capital estrangeiro, recebendo 1,8\% dos afluxos globais em 1990 e 7\% em 1998, e de uma atratividade renovada da América Latina, aumentando sua fatia dos fluxos mundiais de capital, de 4,2\% para 11\%. (Banco M undial 2000, p. 21; U NCTAD 1999: figura 2 e tabela 6.) Ainda não se sabe até que ponto a crise asiática de 1997-98 interrompeu essa tendência, mas isso é improvável. As nuvens da crise ainda pairavam em 1999, quando as fatias de um fluxo de investimentos diretos estrangeiros em crescimento vigoroso, correspondentes ao leste e ao sudeste da Ásia, estavam diminuindo a cerca de $11 \%$ do total mundial (dos quais $4 \%$ para a China), cerca da mesma quantidade que vinha para América Latina, de quase 1/4 (23\%) em 1996. Em termos absolutos, entretanto, o fluxo líquido de investimento direto para os países em desenvolvimento quase quintuplicou em 1999 em comparação com as médias anuais de 1985-1995, de cerca de 30 para 140 bilhões de dólares. Em outras palavras, o investimento estrangeiro direto cresceu de $5 \%$ para $11 \%$ da formação bruta de capital fixo desses países (UNCTAD 2000). 
Todavia, embora uma mudança parcial da direção do capital possa ter conseqüências domésticas de curto prazo de polarização nos países receptores, seus efeitos sobre o crescimento econômico no sul devem diminuir a desigualdade mundial.

0 comércio global acontece em grande parte entre os países ricos. 0 G7 é responsável por metade, e a OECD, por quase três quartos, e nenhum deles foi afetado pelos avanços nas exportações do leste e sudeste da Ásia. A fatia de exportações de ambos em 2000 continua sendo mais ou menos a mesma de 1982 (mesmo descontando-se a recente ampliação da OECD, cerca de dois terços do comércio mundial) (OECD 2000: Annex, Tabela 47; O M C 2000). Asimportações de fora da O PEP e da O ECD, para dentro dos países-membros desta última cresceram modestamente, de 1,6\% do PIB da OECD em 1962, para 2,4\% em 1982, e para 3,4\% em 1999. M as a composição das exportações dos países ricos passou por mudanças fundamentais desde o período clássico. Em 1998, dois terços das importações dos países de alta renda da OECD, de países de renda baixa e média consistiu de manufaturas, e no caso dos Estados U nidos, três quartos (Banco Mundial 2000b: tabela 6.3).

Esse novo padrão de comércio fez surgir discussões sobre os efeitos distributivos da concorrência global de salários (W ood, 1994). Ron Jones (2000) nos tem mostrado que mesmo os modelos comerciais plausíveis têm efeitos ambíguos. Os últimos resultados do debate parecem ser de que, em uma comparação entre os países ricos da OECD, há um efeito estatístico importante de desigualdade em termos de importações de países em desenvolvimento, mas esse efeito desaparece se tomarmos a Europa O cidental isolada, ou seja, ele não se sustenta no caso de estados desenvolvidos baseados no bem-estar social (Gustafsson e Johansson, 1999).

0 efeito das exportações bem-sucedidas sobre a distribuição doméstica no sul também parece variar. Embora sua visão geral ampla dos dados pareça um tanto inconcludente, Adrian W ood (1994, caps. 6.2-6.4) tende a considerar o efeito equalizador, para o Sul, das exportações de manufa- 
turas no sentido Norte. Bhanoji Rao (1999), por outro lado, estudando as várias fontes sobre ganhos e rendas no sudeste da Ásia, apresenta um quadro predominante de variação nacional e intra-regional persistente, com poucas tendências nacionais marcadas pela passagem do tempo, neste caso, do final da década de 60 até o final da de $90^{7}$. Em outros países de renda média do sul, como o M éxico e a Turquia, as aberturas comerciais na verdade aumentaram a dispersão dos ganhos e a desigualdade de renda (Banco M undial 2000a, p. 71). U ma abordagem analítica global dessa questão ainda está em estágio embrionário.

O fluxo transnacional de conhecimento é ainda menos estudado, embora John M eyer (2000) e seu grupo de colaboradores tenham investigado a difusão das concepções de organização e de instituições, como 0 fornecimento de scripts sociais para os atores de uma sociedade globalmente conectada. A difusão da educação e dos sistemas e currículos educacionais foi observada a partir desse ângulo (M eyer et al, 1992). 0 desenvolvimento da alfabetização em massa na maior parte do mundo durante a segunda metade do Século XX foi parte dessa tendência, e uma contribuição importante para uma distribuição mais igualitária das capacidades humanas, mas também, é claro, fundamentalmente um esforço nacional em casos de peso, como o da China Comunista.

O fluxo global de conhecimento médico foi mais específico, tendo tido que enfrentar, e ainda enfrentando, obstáculos importantes derivados da distribuição distorcida de direitos de propriedade e recursos para a pesquisa. Não obstante, o fluxo de conhecimento médico é o principal responsável pelo fato de que os riscos e a expectativa de vida infantis estejam distribuídos de forma muito mais equilibrada do que a renda em todo o mundo. O ssprays (por exemplo, contra os insetos transmissores da M alária), as vacinas, a penicilina e outros tratamentos antibióticos, bem como

7 Taiwan faz parte atualmente da Luxemburg Income Survey, bastante semelhante. Seus dados apresentam apenasum pequeno aumento na desigualdade entre 1981 e 1995, de um índice Gini de 26,7 para 27,7. Este é um nível de desigualdade que está entre a Escandinávia e o resto da Europa 0 cidental ou, em outras palavras, muito próximo da Inglaterra anterior à chegada da Sra. Tatcher (LIS internet database). 
um maior conhecimento do papel do saneamento e da higiene no contágio de doenças infecciosas, com a difusão do conhecimento e das técnicas em to do o mundo, tiveram um grande efeito nas taxas de mortalidade.

O período posterior à Segunda Guerra M undial foi crucial, e o caso mais espetacular foi o do Ceilão (o atual Sri Lanka) e sua campanha antiM alária no pós-guerra, entre outros. Em 1945, a taxa de mortalidade bruta era de 21,5 (mortes por 1000 habitantes), quase exatamente a mesma de 1939; em 1947, havia diminuído para 14, pela primeira e última vez. Em 1950, estava em 12,4 , e no final da década de 1950, havia caído para menos de 10. A taxa da Índia, também, que para o período de 1930-1945 havia oscilado em valores entre 21 e 25, chegou a 16 entre 1949-1950. Hong Kong, em 1939, tinha uma taxa de mortalidade de 30, em 1946, de 11 (Chesnais, 1992: tabela A3.11). Mudanças semelhantes ocorreram em outras partes do sudeste asiático. No caso da África, poucos são os dados confiáveis sobre a demografia histórica. O s dados que parecem mais seguros so bre a Tunísia e o Egito apresentam um declínio na taxa de mortalidade de 27-28, durante a Segunda Guerra Mundial, para 18-19, em 1960 (Allman 1978, p. 12; Banco M undial 1978: Tabela 15) ${ }^{8}$. Na África oriental, as taxas de mortalidade nos anos 20 parecem ter sido estabelecidas durante a década de 50, com um índice bastante baixo, de 18, no Q uênia, em 1962. O Congo Belga provavelmente teve uma taxa de 26 em 1955-57 e a Costa do Marfim, de 29. Mas as regiões da África Central e O cidental tenderam a taxas de mortalidade acima dos 30 por 1000 habitantes às vésperas da independência (Coale e Lorimer 1968: tabela 4.2; Banco Mundial 1978: tabela 15).

Em algumas partes do Caribe, como em Cuba e na Jamaica, as taxas de mortalidade caíram já no período entre-guerras, mas os números exatos informados nas estatísticas não são dignos de confiança. Por exemplo, uma taxa de mortalidade em Cuba em 1930 abaixo de todos os países da

8 Chesnais (1992, p. 568) fornece números relativosao Egito abaixo de 20 para toda a década de 50 e um número inacreditavelmente baixo para a Tunísia, de 8 para o período 1952-54, e de 10 para 1960. 
Europa, com exceção da Holanda, não soa convincente (Chesnais 1992: tabelas A3.4 e A3.9). A trajetória Mexicana é provavelmente mais representativa, já que uma taxa em torno de 22 durante a Segunda Guerra desceu para cerca de 15-16 em 1950-53.

Resumindo, o fluxo de conhecimento médico cumpriu um papel importantíssimo, se não único, no processo mais importante de produção de igualdade no mundo. A difusão dos anticoncepcionais poderia ser mais um exemplo, e também influencia muito a distribuição de oportunidades de vida per capita no mundo. O utro seriam as colheitas de alta produtividade, produzidas pela Revolução Verde da década de 60 , muito importante no sul da Ásia. Em 1900, a diferença de expectativa de vida entre a Índia e a França era de 24 anos, o que naquela época significava que um francês viveria duas vezes mais do que um indiano. $\mathrm{Na}$ metade do Século, um pouco antes da difusão efetiva de conhecimento médico para a Ásia, a diferença era ainda maior, em torno de 34 anos e no final do Século XX, ela estava em 15-16 anos (Mari Bhat, 1989, p. 92; ONU 1951: tabela 29; Banco Mundial 2000: tabela 2). De 1960 a 1997, a expectativa de vida entre todos os chamados países em desenvolvimento subiu de 46 para 62 anos, e a diferença em relação aos países ricos industrializados caiu de 24 para 12 anos. A expectativa de vida foi uma das poucas histórias de sucesso de longo prazo da África independente. Entre 1960 e 1998, a expectativa de vida na região SubSaariana havia subido de 40 para 50 anos, mas a diferença em relação aos países ricos foi mantida em 28 anos (UNDP 1996: tabela 47; UNDP 1999).

Para a população mundial como um todo, a expectativa de vida no momento do nascimento subiu de 55 para 66,6 anos, entre 1962 e 1997. O coeficiente Gini (uma medida mais utilizada para a desigualdade de renda, na época em 0,2 para os países mais igualitários, e 0,6 para os menos) para a desigualdade na expectativa de vida entre as nações do mundo desceu, de 0,24 para $0,11^{9}$. Essa equalização vital é impressionante, e constitui um sinal positivo importante de desenvolvimento global, do

9 Cálculos de A. Melchior et al. Globalisering og ulikhet, 0 slo, U trikesdepartementet, 2000, p. 79. A fonte de dadosé a edição de 1999 dosindicadores do Banco Mundial. 
ponto de vista igualitário. Para precisá-la, é necessário observar as mudanças negativas da década de 90, na Europa do leste pós-comunista, especialmente na ex-URSS e nos Balcãs, além da África atingida pela Aids, especialmente na região sul. Até o momento, essas últimas evoluções apenas diminuíram, sem interromper, o declínio do índice Gini para a expectativa de vida global.

A experiência africana na última década poderá estar anunciando uma mudança no fluxo de conhecimento, para pior, já que enquanto os fluxos econômicos tradicionais podem estar-se voltando no sentido de menos desigualdade, o fluxo de conhecimento poderá estar se transformando na direção oposta. 0 sinal dessa mudança é um fluxo novo de doenças, ainda misterioso, a difusão da Aids, que atingiu com particular gravidade o sul e oeste da África. Embora haja grandes esforços internacionais para controlar este fluxo, ainda não existem medicamentos de combate à doença que sejam acessíveis aos doentes africanos. A epidemia tem conseqüências catastróficas em alguns países do continente. $\mathrm{Na}$ última década, a expectativa de vida no momento do nascimento diminuiu em 21 anos(!) em Botswana, 8 no Q uênia, 2 em M oçambique, 5 na Tanzânia, 10 em Zâmbia e 12 anosnos Zimbábue (Banco Mundial 1990: tabela 1; Banco M undial 2000: tabela 2). Isso significou uma nova ampliação na diferença entre o índice da África Sub-Saariana como um todo e o mundo rico, de 25 anos no final da década de 80, para 28 no final da década de 90.

O s centros de produção do conhecimento científico estão localizados nas partes ricas do mundo, especialmente nos Estados U nidos. De 371 ganhadores do Prêmio Nobel em Ciência e em Economia, entre 1946 e 2000,218 , ou $55 \%$, trabalhavam em instituições americanas e 139 , ou $37 \%$, em instituições da Europa 0 cidental. A dominação americana aumentou nos últimos anos, e de 61 ganhadores de 1994 a 2000, 45 trabaIhavam nos Estados U nidos e 13 na Europa O cidental (os outros 3 eram um físico no Canadá, outro na Rússia e um químico no Japão). Esse centros 
também oferecem educação superior para estudantes de outras partes do mundo, o que é um benefício para estas, se os cientistas e acadêmicos formados retornarem. Até onde isso acontece, e até onde os melhores são selecionados por instituições e empresas americanas e européias, só se sabe em parte. Mas o risco de que aconteça uma fuga dos "cérebros" do mundo pobre aumentou no último World Migration Report, informando que cerca de 23.000 acadêmicos por ano estão deixando atualmente a África (International O ffice of Migration 2000).

\section{0 poder dos entrelaçamentos globais}

A proliferação de Estados-nação posterior à segunda guerra mundial foi seguida por um entrelaçamento intrincado destes estados formalmente soberanos em uma série de redes internacionais. Algumas são institucionalmente regionais, como a U nião Européia, algumas são informalmente regionais, como os contágios das crises regionais, dos quais a crise no sudeste da Ásia em 1997-98 é o último grande exemplo. Algumas são categóricas, como o Country Club dos ricos da O ECD. O utras são globais, constituindo entrelaçamentos globais em um sentido mais estrito, como as clientelas dos poderes supremos da Guerra Fria ou os teatros de operação de organizações globais internacionais importantes e ricas, como o FMI e o Banco Mundial, as organizações da ONU, ou ONGs, como a International Planned Parenthood Federation.

É esta interligação de soberania nacional e dependência extra-nacional que proporciona os entrelaçamentos. Como regra geral, se não por princípio intrínseco, a dependência é bastante assimétrica, mas seria um erro moral-político, bem como analítico, excluir o governo nacional e sua responsabilidade, mesmo em relação a poderosas forças externas como 0 FMI. Até mesmo a dívida externa tem origem nacional, nas decisões de receber, utilizar ou consumir empréstimos. 
Os entrelaçamentos e relacionamentos em rede, em nível global, definem o padrão dos fluxos de comércio, capital e populações, através dos caminhos das corporações transnacionaise, por exemplo, pelas antigas conexões coloniais (cf. Kritz et al., 1992). 0 acolhimento dos fluxos de conexões globais em localidades, de "cidades globais", comunidades diaspóricas ou guetos de imigrantes, também produz entrelaçamentos globais simultaneamente locais, gerando processos locais de desigualdade. Nesse caso, gostaria de destacar alguns mecanismos específicos. Três deles parecem particularmente importantes.

O estabelecimento de agendasnacionais em nível global (ou internacional) é um deles. Uma diretriz global dirige um foco crítico para uma situação nacional e o traz para a agenda nacional através de seu acesso especial ao processo nacional de formulação de políticas. A O ECD tem utilizado esse procedimento para pressionar pela flexibilização no mercado de trabalho, pelo gerenciamento competitivo de serviços públicos e níveis mais baixos de tributação. A estrutura global das Nações U nidas o está utilizando para propósitos de melhoria e promoção da igualdade, estabelecendo alvos distributivos para, por exemplo, serviços de água e saneamento, vacinação, nutrição, educação de meninas e redução da pobreza em geral. Esses alvos muitas vezes não são atingidos, mas as tentativas de sua obtenção têm envolvido uma mobilização transnacional de recursose alguma pressão sobre os Estados- $N$ ação. Essa combinação de foco com objetivos costuma visar uma distribuição menos desigual, embora pudesse funcionar de ambas as formas, em princípio, como todos os outros mecanismos nesse contexto,.

A construção de instituições é um segundo mecanismo, de elaboração e prescrição de certos tipos específicos de instituições nacionais. No passado recente, essa construção em nível global assumiu duas formas principais, com orientações distributivas tendencialmente opostas. Uma delas aponta para uma liberalização do mundo, pressiona pela desregulamentação, privatização e abertura de fronteiras. A remoção de 
barreiras a empresas e mercados tem sido o principal impulso (uma visão geral crítica séria dos efeitos pode ser encontrada em Cornia, 1999). 0 FM I e o Banco Mundial e, por trás deles, o governo dos Estados U nidos (cf. W ade, 2000), têm sido as principais forças dessa tendência.

A outra variante cresceu na família das $N$ ações U nidas e está relacionada à diminuição de barreiras aos indivíduos, com o desmantelamento da exclusão social e a diminuição de hierarquias. Trata-se do movimento pelos direitos humanos em geral e, mais especificamente, por categorias fracas e discriminadas, como as mulheres, as crianças, as minorias étnicas, os trabalhadores migrantes. As conferências e as convenções das $\mathrm{N}$ ações Unidas têm sido instrumentos importantes nesse sentido. A igualdade de gênero e o fortalecimento para o poder dos pobres foram incorporadas muito recentemente à agenda do Banco Mundial (2000a: Parte III).

Em terceiro lugar, está a prescrição de políticas, em termos concretos. Este mecanismo foi desenvolvido e aplicado em grande escala na década de 80, nas "políticas de ajuste estrutural" prescritas aos países africanos e latino-americanos pelo FMI e pelo Banco Mundial, e foi também aplicado pelo FMI em outra grande operação na crise do Leste da Ásia, da Tailândia à Coréia, entre 1997 e 98. Entretanto, antes disso, houveram outras prescrições de políticas importantes e eficazes. As mais significativas foram as políticas de controle de natalidade, impulsionadas internacionalmente a partir do início da década de 60 pelo Banco M undial, pelos governos norte-americano e protestantes da Europa, importantes O NGs, como a International Planned Parenthood Federation. Essas políticas finalmente obtiveram a aceitação mundial entre as Conferências Populacionais de Bucareste, em 1974, e do M éxico, em 1984.

0 estabelecimento de agendas, a construção de instituições e a prescrição de políticas operam através de formas tangíveis de pressão, por intermédio de assessores (convidados ou impostos), através de iniciativas e auxílios econômicos, bem como através de sanções como recusa de crédito, exclusão de membros ou crítica pública. 0 efeito distributivo líquido é 
difícil de avaliar, os alvos e as políticas da ONU em questões específicas e em relação a populações tiveram com certeza um efeito equalizador, mesmo que os objetivos muitas vezes não tenham sido atingidos. As mulheres são vencedoras nesse tipo de globalização; o impacto imediato das intervenções do FMI, incluindo a última na Ásia, tem sido geralmente regressivo, enquanto seus efeitos de médio prazo são desiguais. Ultimamente, tem havido uma preocupação distributiva maior no interior dessas poderosas organizações internacionais, mas as recentes saídas de duas pessoas de destaque nessas áreas do Banco Mundial, Joseph Stiglitz and Ravi Kanbur, indicam os limites.

A ajuda oficial direta tem tido um efeito importante, ainda que de curto prazo, em vários países pobres. Em 1990, ela chegava a um décimo do PIB da África Sub-Saariana; em 1998, havia descido para 4\% e, para todos os países de baixa renda do mundo, a ajuda internacional perfaz apenas $1 \%$ de sua renda nacional. Entretanto, para alguns países individualmente, o número ainda bastante significativo, 28\% do PIB da Nicarágua e de Moçambique em 1998, um quarto do M alawi, um quinto da Eritrea e da Mongólia, um oitavo da Tanzânia e um décimo do Haiti e do Senegal (Banco M undial 2000a: tabela 21).

\section{A capacidade de resistência e a diferença das nações}

0 mecanismo de desigualdade não precisa, de forma alguma, ser global, embora possamos ler seus efeitos como um resultado global, como um padrão mundial de desigualdade. Ele pode estar relacionado com mecanismos e dotações, sua utilização em desenvolvimento, com as instituições, com relações de poder, estratégias e decisões, todos em nível nacional. N esse caso, não existe qualquer causalidade global envolvida, embora o resultado seja uma distribuição global, bem como um conjunto de padrões nacionais de distribuição. Até onde houver transações entre países, o conjunto de outras nações constitui um espaço, na forma de estrutu- 
ra de oportunidades, do qual cada ator nacional pode servir-se, com sorte e habilidades variadas. Esses mecanismos nacionais parecem estar implicados nas análises e discussões sobre o crescimento econômico entre as nações, e formam uma parte importante das explicações sobre a distribuição mundial de renda.

No primeiro estudo sobre desigualdade individual global com base em pesquisa de domicílios, Branko Milanovic (1999) conclui que $75 \%$ da desigualdade do mundo (entre indivíduos) deve-se ao país em que vivem, utilizando um uma decomposição de índice Theil, e $88 \%$ no caso da utilização de um índice Gini. Embora verdadeiro de um ponto de vista do Estado-nação, esse número é exagerado, já que uma série de países grandes como a China, a Índia, a Indonésia, Bangladesh e o Egito foram prédivididos entre um país rural e um urbano, o que pode ser útil para outros propósitos.

As sociedades nacionais mais desiguais têm quase tanta desigualdade entre seus cidadãos como o resto do mundo. Para 1993, Milanovic (1999) calculou o índice de desigualdade Gini para o mundo em 0,66. No Brasil, em 1998, o valor correspondente era de 0,60 (Paes de Barros et al., 2000). A África do Sul pós-apartheid e alguns países pequenos, como a República Centro-Africana, a Guatemala, o Panamá e o Paraguai têm uma distribuição semelhante, ou seja, quase tanta desigualdade em seu interior quanto no mundo inteiro (Banco Mundial 2000a: tabela 5; Banco Interamericano de Desenvolvimento 1998, p. 16).

U m efeito potencialmente muito importante dos mecanismos globais distributivos poderia acontecer através de seu efeito sobre a capacidade redistributiva das instituições nacionais. Embora seja uma possibilidade concreta, o frágil debate atual tende a tomá-lo como fato dado.

Para os estados seriamente preocupados com a redistribuição, que após o colapso do comunismo no leste da Europa são principalmente os estados do bem-estar social da Europa 0 cidental, há boas razões para não considerar a diminuição dessa capacidade como um efeito geral e neces- 
sário da abertura econômica. U ma delas é a correlação positiva real entre, por um lado, a postura de abertura econômica ao mercado mundial e, por outro, a proporção das despesas governamentais ou despesas sociais públicas em relação ao PIB. A primeira já foi apresentada em relação ao mundo como um todo, na década de 80 e a última, para a OECD, na década de 90 (ILO , 1997, pp. 78-79; Therborn, 2000c). Nos países-membros mais antigos da O ECD, o montante de exportações em termos de PIB para 1991-97 tem uma relação de 0,26 com o montante de repasses sociais, ao passo que relaciona-se negativamente com a desigualdade (o índice Gini), $r=-0.34$ (Luxemburg Income Survey sobre renda disponível). Pelo menos no caso dos países membros da O ECD, a razão é uma espiral positiva começando com uma combinação feliz de um certo igualitarismo doméstico e ativos comerciais internacionais, onde o sucesso deste proporciona maiores possibilidades para compromissos de classe com benefícios mútuos, com o compromisso dos trabalhadores com a produtividade e a aceitação, por parte dos empregadores, de tributação e salários mais altos.

O utra razão para não abandonar o Estado- $N$ ação sem evidências muito concretas é o fato de que antes da recente onda de globalização havia um crescimento espetacular nos estados membros da OECD, mensurável i.a., no crescimento da parcela de despesas públicas.

M edido em despesa ou em receita públicas, o setor público nos países mais ricos do mundo está em seu nível historicamente mais alto. Para os membros da O ECD na Europa ocidental, na América do norte, no Japão e na O ceania, a média nacional das despesas totais do governo era de $25 \%$ do PIB em 1960. No final do século passado, em 1999, as despesas públicas haviam chegado a $47 \%$. Para os sete países principais, o G7, as despesas aumentaram de $28 \%$ de seu PIB total, atingindo $37 \%$. É verdade que a parcela de despesa em ambos os casos era alguns pontos percentuais mais alta nos anos da recessão no início da década de 90 do que durante a explosão do final da década, mais isso deve ser interpretado como sendo principalmente uma oscilação conjuntural. Em termos de receitas governamentais, a década final do Século XX foi a mais pródiga de todos os tempos. Para o total da OECD, isso significa $37 \%$ do PIB indo para os 
cofres públicos, e para a U nião Européia, 44\% a 45\% (O ECD 1999: tabelas 6.5 e 6.6; O ECD 2000: Tabela Annex 28).

Tanto para a OECD como um todo, como para os 15 países da União Européia, nas 4 últimas décadas do Século XX, o estado cresceu mais rápido do que o comércio exterior, uma relação que é geralmente ignorada quando se fala em globalização. 0 crescimento mais rápido da dependência do comércio externo durante os anos 90 ainda não superou o crescimento maisalto acumulado no interior da O ECD, bem como dos estados da U nião Européia desde 1960, ou desde 1974. Na verdade, o Japão era mais dependente das exportações durante o período de 1960 a 1973 do que durante a década de 90.

Q uadro 3: Crescimento dos Estados e do comércio exterior: 1960-1998

Total de despesas do governo e exportações em proporção ao PIB. Crescimento em 1960-1999. Pontos percentuais desde 1960.

\begin{tabular}{|c|c|c|c|c|}
\cline { 2 - 5 } \multicolumn{1}{c|}{} & Despesa & & Exportações & \\
\cline { 2 - 5 } \multicolumn{1}{c|}{} & OECD & $\begin{array}{c}\text { União } \\
\text { Européia 15 }\end{array}$ & O ECD & $\begin{array}{c}\text { União } \\
\text { Européia 15 }\end{array}$ \\
\hline 1974 & 6.5 & 8.4 & 4.7 & 6.6 \\
\hline 1987 & 12.9 & 16.7 & 4.7 & 7.2 \\
\hline 1999 & 13.1 & 18.5 & 10.6 & 14.0 \\
\hline
\end{tabular}

Fontes: OECD, Historical Statistics 1960-1997, Paris: 1999, tabelas 6.5. e 6.12; OECD, Economic 0 utlook Junho de 2000, tabelas Annex 1, 9, 28, Paris: 2000.

Assim sendo, historicamente, os atuais Estados estão bem equipados com recursos financeiros, de competência administrativa e especialização em termos de políticas ${ }^{10}$. É verdade que a nova volatilidade dos mercados

10 Em sua apresentação do impacto das importações manufatureiras desde o sul sobre o aumento do desemprego no norte entre 1969-73 e 1986-90, Adrian Wood (1994:314ff) obteve uma adequação bastante boa ( $\left.R^{2}=0.60\right)$, com um modelo interativo do desemprego causado por um aumento desse tipo de exportações poderia ser anulado, seja por uma flexibilidade total de salários por políticas mais fortes para o mercado de trabalho. 
financeiros globais tem gerado um aumento geral na imprevisibilidade e incerteza econômicas, tanto para os investidores privados quanto para os Estados. Entretanto, como foi demonstrado pela crise financeira asiática de 1997-98 e por outras recentes, a capacidade pública de lidar com essas crises privadas é muito maior do que era em 1929-31.

A importância distributiva das políticas, instituições e normas distributivas nacionais têm sido enfatizadas de forma persuasiva pelo especialista britânico Anthony Atkinson (1999a, 1999b). Sua história mais eloqüente fala de duas trajetórias distintas sobre renda familiar disponível nos Estados U nidos e no Canadá em um período de 20 anos, de 1977 a 1998. Enquanto a distribuição no primeiro apresenta uma crescente desigualdade nos anos 80, especialmente na primeira metade da década, e uma desigualdade alta mas progressiva nos anos 90, o segundo manteve uma distribuição muito maisigual, com pequenas oscilações, que tendiam para baixo (para mais igualdade) nos anos 80 (Atkinson 1999a, p. 4).

0 quadro muda, com certeza, se examinarmos os países pobres, fracose dependentes do terceiro mundo e da Europa pós-comunista. As crises transnacionais e as políticas impostas de "ajuste estrutural" tiveram efeitos distributivos negativos muito fortes. Mas as evidências mostram que as crises, a dependência externa e o envolvimento com o FMI e as políticas deste para as crises produzem mais desigualdade, ao invés de aumentar os fluxos globais (cf. a seção 3.3 acima). Além disso, a sobrevivência de Cuba comunista, as especificidades da revolução iraniana e a postura autônoma bemsucedida da Malásia durante a recente crise do sudeste da Ásia são todos exemplos da capacidade contínua de recuperação dos regimes nacionais.

\section{Conclusões}

As desigualdades são plurais, assim como as globalizações ou os processos globais. Além disso, têm trajetórias diferentes. Até recentemente, e até o desastre da Aids na África e o trauma da Europa do leste no póscomunismo, a capacidade humana mais elementar, a de sobrevivência, passou por uma equalização muito importante, em sentido ascendente. 
A desigualdade econômica medida em termos de PIB per capita internacional, por outro lado, tem aumentado quase constantemente nos últimos 200 anos.

As desigualdades neste mundo são produzidas por uma série de processos diferentes. Alguns deles, como a difusão do conhecimento médico e agrícola, tenderão a avançar em uma direção equalizadora. A maioria, entretanto, contribuiu para a reprodução das desigualdades históricas no planeta em uma escala jamais vista.

Foi possível identificar e especificar os principais tipos de processos envolvidos, em primeiro lugar, o resultado da história global moderna, em segundo, os fluxos atuais globais atuais (dos quais quatro foram destacados como sendo especialmente importantes) e em terceiro lugar, os entrelaçamentos globais do nacional e do global, através do entrelaçamento de estado, economia e sociedade nacionais, por um lado, e organizações transnacionais por outro. Em quarto e último lugar, os processos nacionais dentro das economias, sociedades e as formulações de políticas nacionais. Por enquanto, o modelo casual é apenas verbal, um destino que desagrada a aqueles que estudam a complexidade social, como os historiadores e sociólogos, em particular, estão acostumados. Mas parece possível fazer algum tipo de avaliação relativa aproximada. Dessa forma, e com os necessários resguardos, parece que a história global e os atuais processos nacionais são os maiores geradores dos atuais resultados globais em termos de desigualdade. Impressiona o fato de que algumas sociedades nacionais, mesmo as pequenas como a Guatemala ou o Panamá, contenham em si quase tanta desigualdade como o mundo todo. Também é verdade, todavia, que a cidadania dos países ricos e pobres, em outras palavras, a desigualdade entre países, seja responsável por grande parte da desigualdade no mundo, ou seja, a cidadania é uma grande instituição da desigualdade.

O s fluxos globais recentes, dos quais apenas um ou dois ocupam um lugar de destaque no discurso dominante sobre globalização, aparecem claramente em segundo lugar em relação à formação histórica e as institui- 
ções nacionais, muito embora o fluxo de conhecimento seja muito subestimado na argumentação convencional. A direção dosfluxos globais parece estar mudando, o que já está claro no que diz respeito à migração, ao passo que os sinais com relação aos outros são mais ambíguos.

O Século XX foi o século histórico do Estado-nação, em seu caminho através do Século XIX, surgindo no final dos impérios dinásticos até a Primeira Guerra Mundial e explodindo no mundo inteiro a partir dos amplos processos de descolonização posteriores à Segunda Guerra, depois estimulado pelo desmantelamento do internacionalismo comunista e fortalecido pelo surgimento do Estado Social, acima de tudo na Europa O cidental, mas em certa medida em todo o mundo rico. A recente e atual onda de globalização não desfez essa era do Estado-nação, ao contrário do que dizem muitas afirmações ideológicas, ao mesmo tempo nostálgicas e triunfalistas. 0 novo século poderá assistir à derrota do Estado-nação, mas ela ainda não aconteceu, com exceção de na Europa do Leste pós-comunista. O s objetos das intervenções do FMI e do terceiro mundo sempre foram, nos tempos modernos, fracos, pobres e externamente dependentes.

\section{Referências bibliográficas}

ALLMAN, J. The demographic transition in the Middle East and North Africa. In: idem (org.), W omen's status and fertility in the muslim world. Nova lorque: Praeger, 1978.

ATKINSO N, A. The distribution of income in the UK and OECD: countries in twentieth century. In: Oxford Review of Economic Policy 15:4, 1999a.

ATKIN SO N, A. Is rising inequality inevitable? A critique of the transatlantic consensus. In: WIDER Annual Lectures 3. Helsinki: UN University, 1999b.

Binational Study on Migration. In: Migration between M exico \& the United States. Washington D.C., 1998.

BO URDIEU, P. La distinction. Paris: Minuit, 1979. 
BOURGUIGNON, F. e MORRISSON, C. Adjustment and equity in developing countries. A New Approach. Paris: OECD, 1992.

CASTLES, S. e MILLER, M. The age of migration. Basingstoke: Macmillan, $2^{\mathrm{a}}$ ed., 1998.

CASTLES, S. Migration as a factor in social transformation in East Asia: artigo à Conference on Migration and Development, Universidade de Princeton, 4-6 de maio, 2000.

CEPAL (UN Economic Commission for Latin America/ECLAC). Panorama social. Santiago de Chile: CEPAL, 1998.

CHESNAIS, J.-C. The demographic transition. O xford: Clarendon Press, 1992.

CO ALE, A. e LO RIM ER, F. Summary of estimates of fertility and mortality. In: BRASS, W. et al., The demography of Tropical Africa. Princeton: Princeton University Press, 1968.

CORNIA, G. A. Liberalization, globalization, and income distribution. In: WIDER W orking Papers 15. Helsinki: UN U niversity, 1999.

DOLLAR, D. e KRAAY, A. Trade, growth and poverty: artigo apresentado à Conference on Poverty and the International Economy em Estocolmo, 20-21 de outubro, 2000.

ECLAC (CEPAL). Social panorama of Latin America. Santiago de Chile: ECLAC, 1997.

FISCHER, C. et al. Inequality by design. Cracking te bell curve myth. Princeton: Princeton University Press, 1996.

GUSTAFSSO N, B. e JO HANSSO N, M. Search of smoking guns: what makes income inequality vary over time in different countries? In: American Sociological Review vol 64, pp 585-605, 1999.

H OBSBAW M, E. The age of empire. London: Weidenfeld \& Nicolson, 1987.

ILO. W orld Labour Report 1997-98. Geneva: ILO, 1997.

ILO. Yearbook of Labour Statistics. Geneva: ILO, 1999. 
Inter-American Development Bank. Facing up to inequality in Latin America. Baltimore: Johns Hopkins University Press, 1998.

International O ffice of Migration. W orld Migration Report 2000. Geneva: 2000.

FMI. World economic outlook. Washington D.C.: FMI, maio de 2000.

JO NES, R. Globalization and the distribution of income: the economic arguments: artigo para o Workshop on Global Processes of Inequality. Estocolmo: 26-29 de outubro de 2000.

KANBUR, R. Income distribution and development. In: ATKINSON, A. e BOURGUIGNON, F. (orgs.), Handbook of Income Distribution vol 1. Amsterdam: Elsevier, 2000.

KRITZ, M. et al. (eds.) International migration systems: a global approach. Oxford: Clarendon Press, 1992.

KRUGMAN, P. Geography and Trade. Leuven and Cambridge, Mass.: Leuven University Press and M IT Press, 1993.

KRUGMAN, P. e VENABLES, A. Globalization and the inequality of Nations. The Q uarterly Journal of Economics CX:4, 1995.

LONDOÑO, J.L. e SZÉKELY, M. Persistent poverty and excess inequality: Latin America, 1975-1995. W ashington D.C.: Inter-American Development Bank W orking Paper 357, 1997.

MADDISO N, A. Monitoring the world economy 1820-1992. Paris: OECD, 1992.

MARI BHAT, P.N. Mortality and fertility in India, 1881-1961: a Reassessment. In DYSO N, T. (org.), India's Historical Demography. Londres: Curzon, 1989.

MELCHIOR, A. et al. Globalisering og ulikhet. O slo: Utrikesdepartementet, 2000.

MEYER, J. Globalization: sources and effects on National Societies and States. In: International Sociology 15, pp.233-48, 2000.

MEYER, J. et al. W orld Expansion of Mass Education, 1870-1980. Sociology of Education 65, pp.128-49, 1992. 
MILANOVIC, B. True world income distribution, 1988 and 1993: first calculations based on household surveys alone. Washington D.C: Banco Mundial, 1999.

M iller, D. Justice and global inequality. In: Hurrell, A. e Woods, N. (orgs. ), Inequality, globalization and world politics. Oxford: OUP, 1999.

NUSSBAUM, M. W omen and human development. Cambridge: CUP, 2000.

O 'RO URKE, K. e W ILLIAMSO N, J. Globalization and history. Cambridge, Mass.: MIT Press, 1999.

OECD. Employment outlook. Paris: OECD, 1997.

OECD. Historical statistics 1960-1998. Paris: OECD, 1999.

OECD. OECD economic outlook. Paris: OECD, Junho de 2000.

PAES DE BARROS, R. et al. Inequality and poverty in Brazil: artigo apresentado à Conference on Global Processes of Inequality em Estocolmo, 26-29 de outubro, 2000.

PATTERSO N, O. Rituals of Blood. Washington D.C.: Civitas, 1998.

RAO, Bhanoji V.V. East Asian economies. Trends in poverty and income inequality. Economic and Political W eekly May 1, 1999.

RAW LS J. The law of peoples. In: SHUTE, S. and HURLEY, S. (eds.), On human rights: the Oxford amnesty lectures 1993. Nova Iorque: O UP, 1993.

RO DRÍGUEZ, F. e RO DRIK, D. Trade policy and economic growth: a skeptic's guide to the cross-national evidence. Dept of Economics, U niversity of M aryland, Kennedy School of Government, Harvard University, 2000.

RO DRIK, D. Comments on DO LLAR, D. and KRAAY, A. Trade, growth and poverty: artigo apresentado à Conference on Poverty and the International Economy, em Estocolmo, 20-21 de outubro, 2000.

SEN, A. Inequality re-examined. Cambridge, M ass.: H arvard U niversity Press, 1992.

SEN. A. Social justice and the distribution of income. In: ATKINSON, A. e BO URGUIGNO N, F. (orgs.), Handbook of income distribution vol 1. Amsterdam: Elsevier, 2000. 
STEW ART, F. e BERRY, A. Globalization, liberalization, and inequality: expectations and experience. In: HURRELL, A. and WOODS, N. (orgs.), Inequality, globalization and world politics. Oxford: OUP, 1999.

THERBORN, G. European modernity and beyond. The trajectory of european societies, 1945-2000. Londres: Sage, 1995.

THERBORN, G. The atlantic diagonal in the labyrinths of modernities and globalizations. In: THERBO RN, G. (ed.), Globalizations and modernities. Estocolmo: FRN, 1999.

THERBORN, G. Globalizations. Dimensions, historical waves, regional effects, normative governance. In: International Sociology 15:151-79, 2000a.

THERBO RN, G. Global processes of inequality: artigo apresentado à Conference On Global Processes of Inequality. Estocoomo: 26-29 de outubro, 2000b.

TILLY, C. Durable inequality. Berkeley: University of California Press, 1998.

UNCTAD. W orld Investment Report 1999. Geneva: 1999.

UNCTAD. W orld Investment Report 2000. Geneva: 2000.

U NDP. Human Development Report. Geneva: UN, 1999.

UNICEF. Crisis in mortality, health and nutrition. Firenze: Unicef Economies in Transition Studies, 1994.

WADE, R. Developing countries autonomy in the choice of market institutions: artigo apresentado à Conference on What can states do now? University of Pennsylvania, 4-6 de maio, 2000.

W ALLERSTEIN, I. The Modern World System. Nova Iorque: Academic Press, 3 volumes, 1974.

W ALZER, M. Spheres of Justice. N ova lorque: Basic Books, 1983.

WOOD, A. North-South trade, employment and inequality. Oxford: Clarendon Press, 1994.

WOOD, A. O penness and wage inequality in developing countries: the latin american challenge to east asian conventional wisdom. World Bank Economic Review 11, pp.33-57, 1997. 
Banco M undial. W orld Development Report 1978. Nova Iorque: O UP, 1978.

Banco M undial. W orld Development Report 1990. Nova Iorque: OUP, 1990.

Banco Mundial. Averting the old age crisis. Nova lorque: OUP, 1994

Banco Mundial. Knowledge for development. Nova Iorque: OUP, 1998

Banco Mundial. Global Economic Prospects. Internet ed., 1999

Banco M undial. World Development Report 2000/2001. N ova lorque: OUP, 2000a.

Banco Mundial. World Development Indicators. Washington D.C.: 2000b.

Organização M undial do Comércio. Annual Report 2000. Genebra: 2000.

\section{Resumo}

0 título do artigo refere-se a três conjuntos de questões fundamentais e controvertidas, não resolvidas entre os cientistas sociais, para não falar dos cidadãos sociais. Duas delas são basicamente conceituais e teóricas, a outra é, ao mesmo tempo, conceitual e empírica.

Em primeiro lugar, o que é globalização? De que forma devemos conceitualizá-la? Em segundo, que tipos de desigualdade podem ser identificados e quais são os mais pertinentes? $\mathrm{E}$, em terceiro lugar, que tipos de processos geram a desigualdade global que estamos observando e vivenciando?

Não podemos esperar encontrar uma resposta direta para qualquer dessas perguntas, já que nenhuma delas a tem. 0 s objetivos deste artigo são 0 de contribuir para o esclarecimento das alternativas, bem com de eventuais implicações para a sua adoção, propor uma determinada abordagem conceitual-analítica e apresentar argumentos empíricos para uma abordagem multifacetada sobre a geração de desigualdade no mundo. A globalização e a desigualdade são duas encruzilhadas das ciências sociais e da filosofia social, abordadas aqui pelo autor a partir de sua formação como sociólogo e cientista político.

Palavras-chave: Globalização, desigualdade. 